\title{
Iniciação científica por meio de elaboração de projetos de pesquisa: um relato sobre a organização da disciplina em um Curso Técnico em Química
}

\section{Scientific initiation through the elaboration of research projects: a report on the organization of the discipline in a Technical Course in Chemistry}

Daniele Trajano Raupp (daniele.raupp@ufrgs.br)

Universidade Federal do Rio Grande do Sul (UFRGS)

\author{
Simone de Souza Borges Rempel (quimica.borges@liberato.com.br) \\ Fundação Escola Técnica Liberato Salzano Vieira da Cunha
}

Resumo: Este relato de experiência objetiva descrever brevemente como a Iniciação Científica é estruturada no Curso Técnico em Química, na Fundação Liberato Salzano Vieira da Cunha, no município de Novo Hamburgo, RS. A partir da discussão das abordagens em sala de aula, da estrutura e apoio da escola, da dinâmica de trabalho com alunos, da compreensão de suas dificuldades, esperamos que este relato possa ser uma contribuição para os professores e pesquisadores com interesse nessa temática. $\mathrm{O}$ primeiro contato dos estudantes com a pesquisa acadêmica pode ser considerado um desafio na Educação Básica e dessa forma a aproximação com a metodologia da pesquisa científica, visando a capacitação e qualificação de jovens talentos demanda esforço da equipe pedagógica e qualificação dos orientadores para fomentar a criatividade e o pensamento científico do estudante, além de motivá-lo para aprendizagem de métodos e técnicas científicas. A Iniciação Científica tem o potencial de ser uma poderosa estratégia na compreensão sobre como a ciência é construída e como os cientistas trabalham em oposição à visão dogmática de uma ciência acabada, possibilitando assim a formação de um cidadão crítico capaz de modo de compreender a utilidade da ciência e sua grande influência em nosso cotidiano e em nossa sociedade.

Palavras-chave: Iniciação Científica; educação básica; projetos de pesquisa.

Abstract: This experience report aims to briefly describe how Scientific Initiation is structured in the Technical Course in Chemistry, at the Liberato Salzano Vieira da Cunha Foundation, in the city of Novo Hamburgo, RS. From the discussion of the approaches in the classroom, the structure and support of the school, the dynamics of working with students, the understanding of their difficulties, we hope that this report can be a contribution for teachers and researchers with an interest in this theme. The first contact of students with academic research can be considered a challenge in Basic Education and, thus, the approximation with the scientific research methodology, aiming at the training and qualification of young talents demands effort from the pedagogical team and qualification of the advisors to foster creativity and the student's scientific thinking, in addition to motivating him to learn scientific methods and techniques. Scientific Initiation has the potential to be a powerful strategy in understanding how science is constructed and how scientists work in opposition to the dogmatic view of a finished science, thus 
enabling the formation of a critical citizen capable of understanding the usefulness of science and its great influence in our daily lives and our society.

Keywords: Scientific initiation; basic education; research project.

\section{INTRODUÇÃO}

A Iniciação Científica (IC) pode ser definida como "um programa que visa desenvolver a criatividade e o pensamento científico do estudante, orientado por pesquisador experiente[...]" (DA SILVA, 2018; p.46). Inicialmente, para compreender o cenário da pesquisa na escola, cabe destacar que no Brasil, a Iniciação Científica, inicia em 1951, com a criação do Conselho Nacional de Desenvolvimento Científico e Tecnológico (CNPq), tendo como objetivo incentivar a pesquisa e, por conseguinte, o desenvolvimento da tecnologia, ciência e educação (DA COSTA; DE FREITAS ZOMPERO,2017). A IC iniciou sendo largamente difundida no Ensino Superior e por muito tempo, esse tipo de iniciativa ficava a cargo das universidades e raramente era levada às escolas de Educação Básica (SEVERINO, 2016). Nesse nível de ensino as feiras de ciências passaram a ser uma forma de desenvolvimento de pesquisas e "são importantes movimentos, pois unem estudantes da educação básica à produção de novos conhecimentos por meio de projetos." (GALLON ET AL, 2019, p.180). Além da possibilidade de aproximação dos estudantes do conhecimento científico, o desenvolvimento dos projetos são uma importante ferramenta já que possuem o potencial de contribuir para o processo de aprendizagem (COSTA; MELLO; ROEHRS, 2019).

A criação de uma feira de ciências no ano de 1978 na Fundação Liberato, foi o início da iniciação científica na escola para aqueles que tinham interesse em realizar pesquisa. Ao longo das três décadas seguintes, a iniciação científica deixa de ser uma atividade opcional, restrita a poucos alunos e em 2009 passa a ser um componente curricular de todos os cursos da escola. Tendo como fio condutor a Metodologia Científica, a disciplina é desafiadora para os docentes visto que, os alunos chegam à escola sem saber pesquisar (DEMO, 2002), com grande dificuldade na elaboração de trabalhos escritos (FERREIRA, C.; FERREIRA, F; SOARES,2017), muitos com a visão de que pesquisa é transcrever o que foi lido, produzindo cópias e fazendo plágio, sem ao menos saber o que isso significa. Isso demanda, conforme afirmam Costa, Mello e Roehrs (2019) o esforço da equipe 
pedagógica para orientar os estudantes na pesquisa de iniciação científica na Educação Básica.

Nesse trabalho pretende-se apresentar as abordagens realizadas nessa disciplina, a estrutura e apoio da escola no processo de pesquisa, a forma de trabalho dos alunos, suas dificuldades e evolução no decorrer do ano letivo bem como a forma de avaliação adotada. Esperamos que a experiência relatada possa ser uma contribuição para os pesquisadores com interesse nessa temática.

\section{ESCOLA E A ORGANIZAÇÃO DA DISCIPLINA}

Localizada na Região Metropolitana de Porto Alegre, com uma estrutura dedicada ao ensino técnico profissional de forma integrada e subsequente, com cerca de três mil alunos matriculados, provenientes de mais de 50 municípios do Rio Grande do Sul. De forma integrada, o ensino ocorre articulado ao nível médio, voltado para estudantes do ensino fundamental. A duração do curso é de quatro anos mais a prática supervisionada (estágio). O Curso Técnico de Química, fundado em 1967, , busca desenvolver as habilidades necessárias para a operação, monitoramento e controle analítico de processos industriais, bem como a prestação de serviços de assistência técnica nas áreas industrial e comercial, controle de qualidade de insumos e produtos e ao desenvolvimento de projetos de pesquisa em diferentes tecnologias de produção, com base nos princípios de gestão e preservação ambiental (LIBERATO, 2020a).

A IC na escola, é uma realidade há décadas. No ano de 1978 foi realizada a primeira FEICIT - Feira interna de Ciência e Tecnologia, com a apresentação de 277 projetos. Em 1885 a feira passou a ser estadual, contando com projetos de alunos de ensino médio de todo estado do Rio Grande do Sul, passando a denominar-se-MOSTRATEC-Mostra de Rriatividade em Ciências, Arte eTechologiąEm 1993, visando contemplar escolas do Brasil interessadas em divulgar os projetos desenvolvidos em sala de aula, promove-se a feira com de caráter nacional. Em 1994 a MOSTRATEC passa a receber trabalhos de outros países, projetando-se como um dos principais eventos educacionais do país e recebendo o nome de Mostra Internacional de Ciência e Tecnologia (MOSTRATEC,2020). 
Mesmo com essa tradição de longa data, a iniciação científica não ocorria de uma forma sistemática e a disciplina intitulada "Projetos" foi incluída nos planos dos cursos técnicos da Fundação somente a partir de partir de 2009. No curso técnico em química, atualmente, a disciplina consta como componente curricular - Projetos de Pesquisa - no primeiro ano e no segundo ano, totalizando 80 horas ao longo do curso. No quadro 1 estão descritas as competências e habilidades a serem desenvolvidas ao longo dos dois anos.

QUADRO 1 - Competências e habilidades da disciplina.

\begin{tabular}{|c|c|}
\hline Competências Específicas & Habilidades \\
\hline $\begin{array}{l}\text {-Conhecer os diferentes tipos de conhecimento; } \\
\text { - Reconhecer o papel do conhecimento científico e } \\
\text { da pesquisa; } \\
\text {-Compreender e aplicar a metodologia científica } \\
\text { na elaboração de uma pesquisa; } \\
\text { - Desenvolver um plano de pesquisa; } \\
\text { - Realizar pesquisa de acordo com o plano; } \\
\text { - Elaborar um relatório de pesquisa; } \\
\text { - Usar técnicas de apresentação oral, visual e } \\
\text { escrita. }\end{array}$ & $\begin{array}{l}\text {-Diferenciar os tipos de conhecimento: científico, popular, religioso e } \\
\text { filosófico; } \\
\text { - Compreender o processo de construção do conhecimento científico; } \\
\text { - Aplicar a metodologia científica como um instrumento de trabalho na } \\
\text { busca do conhecimento, utilizando um pensamento crítico; } \\
\text { - Identificar e elaborar: problema, hipóteses, variáveis, justificativa, } \\
\text { objetivos de acordo com os preceitos científicos; } \\
\text { - Realizar revisão de literatura e aplicar o conhecimento na elaboração de } \\
\text { textos referenciados; } \\
\text { - Compreender e classificar os diferentes tipos de metodologia quanto à } \\
\text { natureza da pesquisa (básica, ou aplicada), quanto à abordagem do } \\
\text { problema (qualitativa ou quantitativa), quanto aos objetivos ( exploratória, } \\
\text { descritiva, explicativa), quanto aos procedimentos ( bibliográfica, } \\
\text { experimental, estudo de caso, levantamento, estudo de campo, ex-post- } \\
\text { facto); } \\
\text { - Conhecer, desenvolver e aplicar instrumentos de coleta de dados } \\
\text { (questionários, entrevistas, observação, fontes bibliográficas e } \\
\text { documentais, execução de experimentos). } \\
\text { - Interpretar e discutir os dados coletados durante o processo de pesquisa; } \\
\text { - Elaborar conclusão relacionando com as hipóteses e respondendo o } \\
\text { problema de pesquisa; } \\
\text { - Aplicar as Normas Técnicas para a redação e apresentação de relatórios } \\
\text { e textos técnicos; } \\
\text { - Usar técnicas de apresentação oral, visual e escrita em um projeto de } \\
\text { pesquisa bibliográfica. }\end{array}$ \\
\hline
\end{tabular}

Até o ano de 2013 os alunos desenvolviam o projeto, coletavam dados e faziam o relatório em ambos anos. No entanto percebeu-se que em virtude da pequena carga horária, o aprendizado não estava sendo significativo. Constatação baseada nos problemas ao desenvolver uma pesquisa quando esses alunos chegavam no quarto ano. Pois além de desenvolver projetos na disciplina, a realização de uma pesquisa é uma das modalidades de trabalho de conclusão de curso (TCC) que deverá ser apresentado ao final do $4^{\circ}$ ano. Por esse motivo, as professoras da disciplina em conjunto com o setor pedagógico, decidiram alterar a dinâmica da mesma, e essa passou a ter o formato aqui apresentado. 


\subsection{O PRIMEIRO ANO E A MOTIVAÇÃO PARA A PESQUISA}

No primeiro ano o objetivo passou a ser despertar o interesse pela pesquisa. Assim há uma introdução aos conceitos de ciência e pesquisa, e ao final do ano letivo o aluno deverá apresentar um plano de pesquisa completo observando as normas da ABNT. No entanto, a ênfase desse primeiro contato com iniciação científica é a familiarização do aluno com o que é uma metodologia científica e como se estrutura um plano de pesquisa.

Iniciamos de maneira bem didática introduzindo conceitos básicos de ciência e pesquisa. No primeiro trimestre os alunos elaboram alguns trabalhos para definir metodologia científica e a treinar como formatar trabalhos, como usar referências, o que é plágio, ética e segurança na pesquisa. Utilizamos um Vídeo do Youtube da UFRJ: Luz, trevas e o método científico para discussão sobre ciência ${ }^{1}$. A carga horária de 50 minutos semanais limita um pouco o desenvolvimento das atividades e por isso os alunos têm que realizar algumas tarefas extraclasse. Uma dela é a realização de um curso on-line na Plataforma Interativa em Ciências e Engenharia - APICE: Metodologia de Pesquisa e Orientação de Projetos de Iniciação Científica (Figura 1).

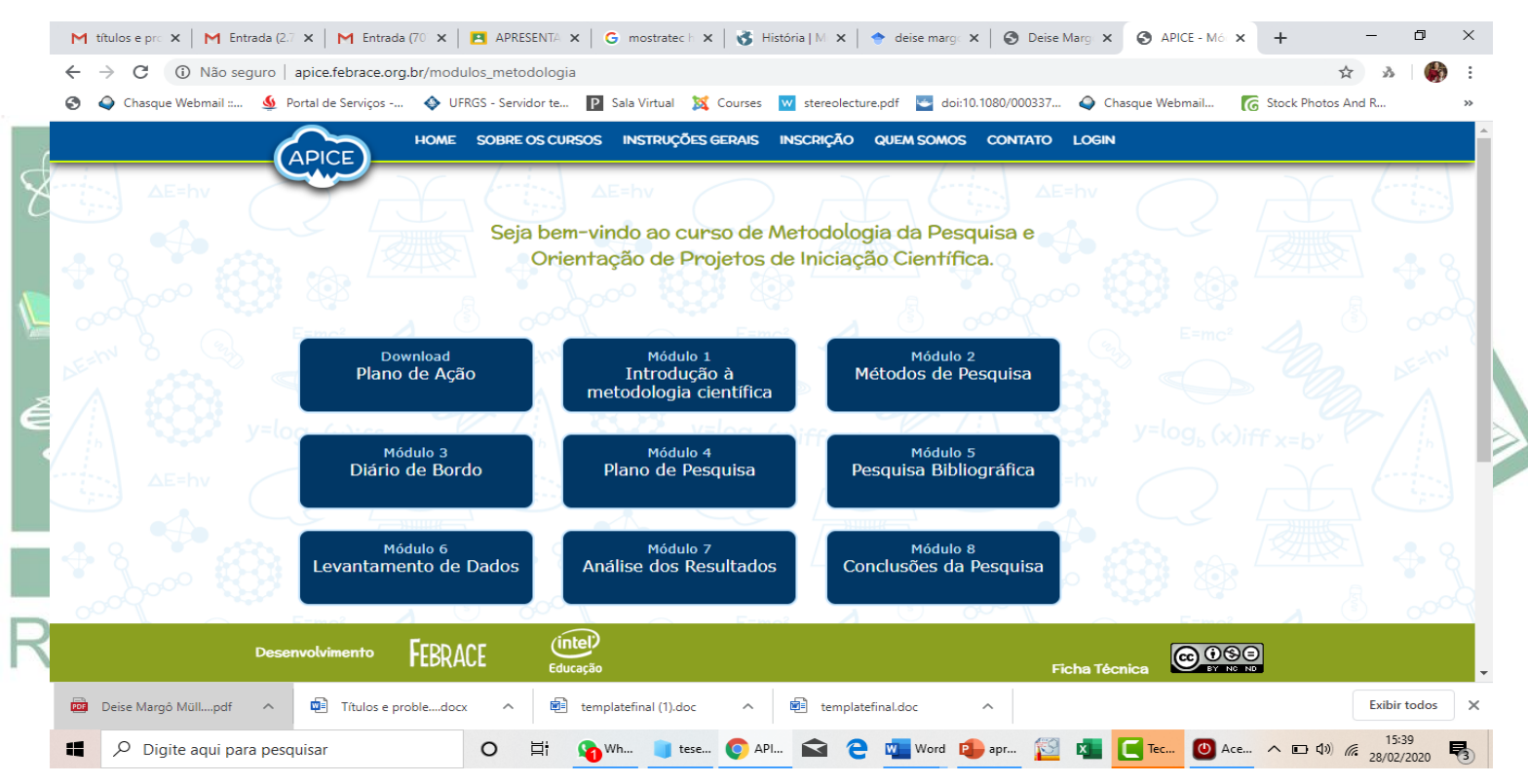

Figura 1 - Curso de metodologia científica da Febrace Fonte: FEBRACE (2020)

\footnotetext{
${ }^{1}$ Disponível em http://www.youtube.com/watch?v=xLZYsCn2Y4g
} 
Com uma linguagem dinâmica (fotos e vídeos) e atividades interativas, a APICE oferece conteúdo para apoiar o desenvolvimento de projetos de iniciação científica nas escolas. Como forma de organizar a comunicação e as atividades, utilizou-se a plataforma Google sala de aula.

No segundo trimestre inicia-se o projeto que é desenvolvido em grupos de 4 alunos, formados por afinidade entre eles e o tema escolhido é livre, desde que esteja relacionado com uma das áreas de pesquisa da escola, que são: Ciências Animais e de Plantas, Biologia Celular e Molecular, Microbiologia, Bioquímica e Química, Ciências da Computação, Ciências Planetárias, Terrestres e Matemática e Física, Ciências Sociais, Comportamento e Arte, Engenharia Elétrica, Engenharia Eletrônica, Engenharia Mecânica, Engenharia e Materiais, Gerenciamento do Meio Ambiente, Ciências Ambientais e Saúde.

A estrutura do projeto é composta por: tema, justificativa, problema, objetivo geral e específicos, revisão de literatura, metodologia e referências. O projeto após corrigido pelo professor é encaminhado para o Comitê de ética e segurança na pesquisa (CESP) com o objetivo de revisar o plano de pesquisa antes que seja executado. Os alunos também são orientados a utilizar o Caderno de Campo, que também é avaliado nesse trimestre. $\mathrm{O}$ professor da disciplina também é o orientador de todos os trabalhos.

Sobre a revisão de literatura orienta-se a busca em artigos científicos, TCC, teses e dissertação como material mais adequado e confiável para consulta, utilizando o Google acadêmico como ferramenta de busca. Além disso, o texto produzido deve ser analisado pelo CopySpider, um Software gratuito detector de plágio, com a finalidade de analisar a existência de cópias de outros textos disponíveis na internet.

Por/fim, no terceiro trimestre a avaliaçâô |consiste na entrega do projeto corrigido e aprovado pelo CESP em um texto impresso e apresentação do mesmo para turma (Figura 2). 


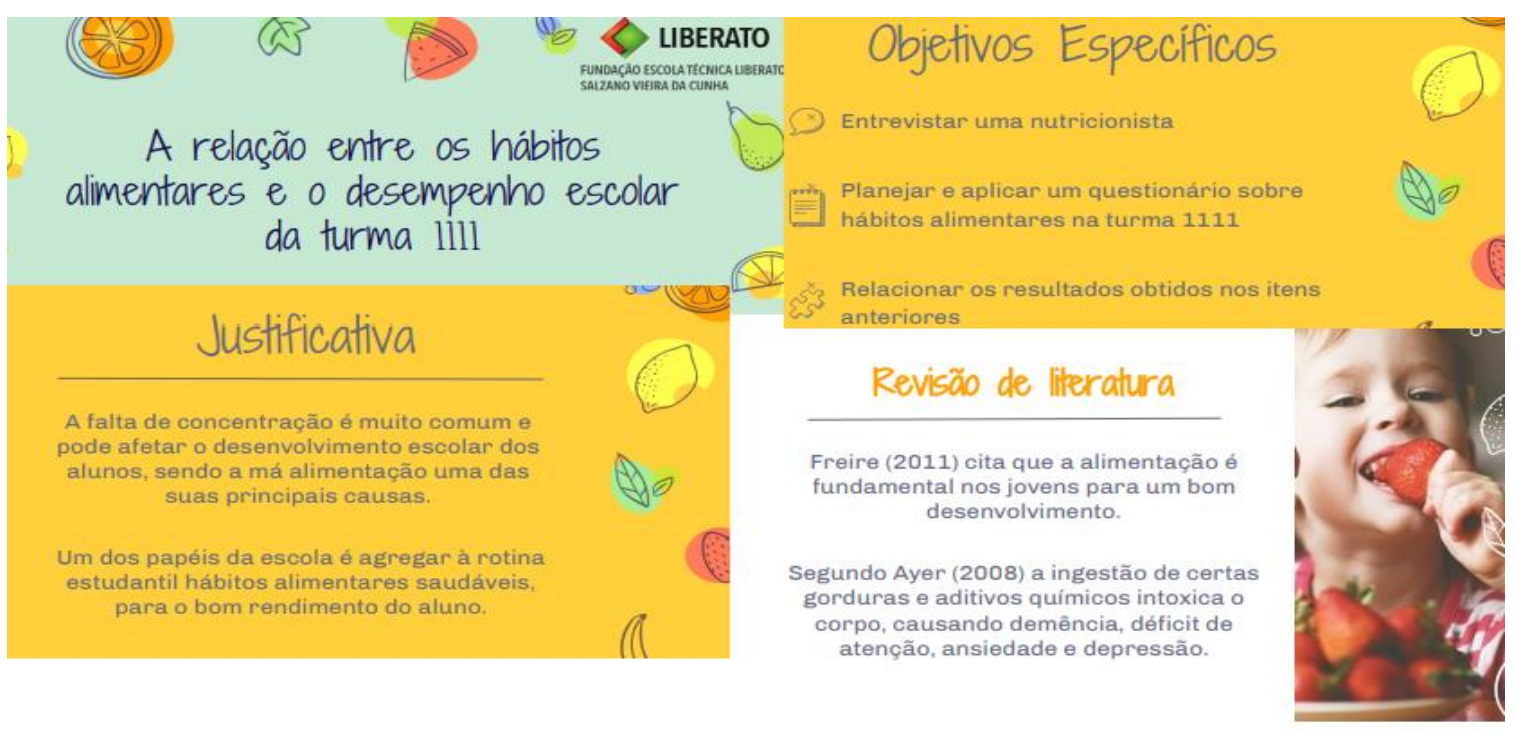

Figura 2 - Apresentação de um projeto da turma Fonte: Autoras (2020)

Dessa forma ao final do primeiro ano, espera-se que o aluno esteja familiarizado com o conceito de método científico e as etapas necessária para a realização de uma pesquisa.

\subsection{O SEGUNDO ANO E A ORGANIZAÇÃO DA PESQUISA CIENTÍFICA}

No segundo ano, os alunos desenvolvem um plano de pesquisa que pode ser baseado no plano do ano anterior, caso exista interesse e o grupo permaneça o mesmo, ou elaboram um novo plano. Nesse ano eles também realizam a pesquisa planejada e apresentam um relatório final e há a exigência de que pesquisa que tenha algum tipo de experimento, para que possa desenvolver a metodologia, observar os resultados e elaborar a conclusão. Para auxílio no tema com referências ou atividades práticas no laboratório, os alunos podem convidar algum professor da instituição para que oriente sua pesquisa; que partilha com o professor da disciplina essa tarefa.

As aulas do segundo ano começam com uma pequena revisão do plano de pesquisa do ano anterior e orientações das exigências deste ano letivo, sendo que assim como no primeiro ano os alunos também trabalharam em grupos de 3 ou 4 alunos, conforme a disponibilidade nas turmas. No primeiro trimestre os alunos têm que entregar um préplano de pesquisa para avaliar as possibilidades de execução do mesmo e o caderno de campo que consta o planejamento do projeto e um esboço de referencial teórico, esse pré- 
plano deve conter: tema, justificativa, problema, hipóteses e objetivos. Já no segundo trimestre os alunos apresentam o plano de pesquisa completo, que deveria conter: tema, justificativa, problema, hipóteses, objetivos, referencial teórico, metodologia, análise de dados e análise de risco. Até o final do trimestre o plano deverá ser submetido ao CESP, entregue uma cópia impressa para verificar formatação e encerramos com a apresentação oral e slides para turma e professor. É importante salientar que a metodologia exigida no segundo ano deve ser executada e observado os resultados.

Já no terceiro trimestre o aluno após receber a autorização do CESP para a execução prática da pesquisa deverá encaminhar a metodologia, observar os resultados, redigir e entregar o relatório final que deve conter: Introdução, referencial teórico, metodologia, análise de dados, resultados e conclusão. No final do trimestre os alunos apresentam o relatório final e entregam uma cópia impressa. A avaliação é feita no decorrer das aulas, pois os alunos trabalharam no laboratório de informática e o professor pode acompanhar o desenvolvimento dos mesmos.

No final dos trimestres, serve também como instrumento de avaliação o caderno de campo, apresentação oral do trabalho e o plano ou relatório impressos, para avaliar a formatação. Critérios de avaliação importantes são: o compromisso, pontualidade, trabalhar em grupo, a coerência no plano de pesquisa, execução da metodologia, desempenho na apresentação oral e as normas da ABNT. No final do segundo trimestre ocorre a FEICIT (Feira Interna de ciência e Tecnologia) e os alunos são incentivados a participar na Modalidade Iniciação Científica. Para participar dessa modalidade é exigido apenas o plano de pesquisa, sem haver necessidade de a metodologia ter sido executada (Figura 3).

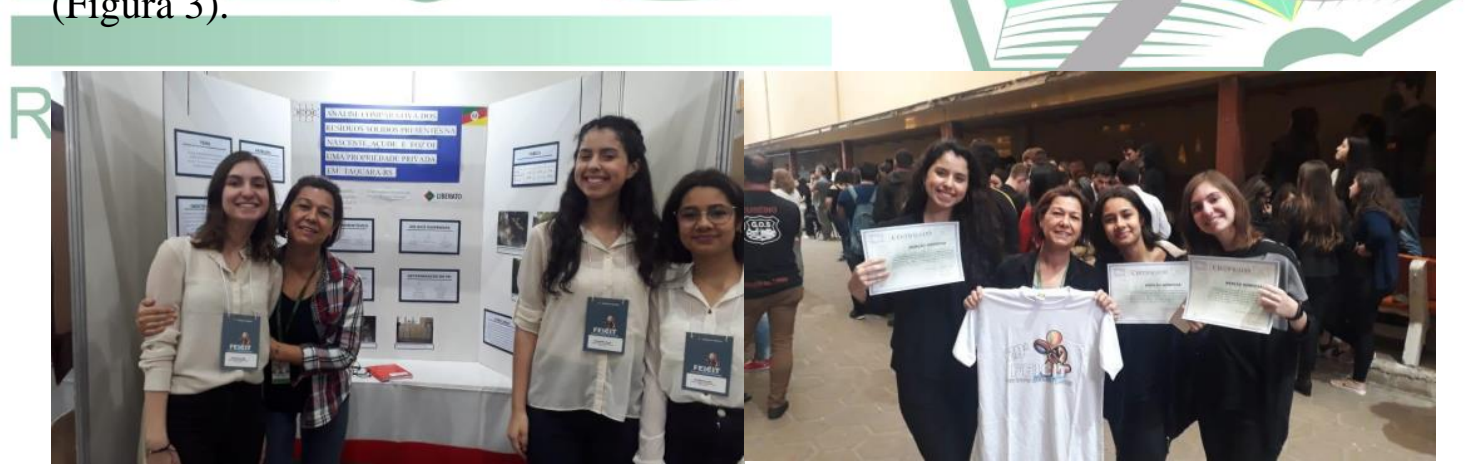

Figura 3 - Participação de premiação de grupo na FEICIT Fonte: Autoras (2020) 


\subsection{O APOIO DA ESCOLA}

O professor da disciplina tem direito a um período de 50 minutos de planejamento para cada dois períodos de sala de aula, devido o extenso trabalho de orientação e correção. A escola, pela cultura de Feiras e Mostras, conta com o Comitê de Segurança e Ética na Pesquisa (CESP) que é responsável por revisar e autorizar a execução de práticas. Sendo assim, "o foco desta revisão é verificar se os alunos pesquisadores previram os possíveis riscos envolvidos na execução de sua pesquisa e quais as medidas a serem adotadas para proteção e segurança dos participantes da pesquisa, do meio ambiente e das instituições nas quais envolvem o trabalho" (LIBERATO, 2020b, p.2). A escola também busca forma de ampliar o número de vagas para participação da FEICIT na modalidade Iniciação científica, visando motivar os alunos no desenvolvimento e divulgação de suas pesquisas.

\section{ANÁLISE E DISCUSSÃO DO RELATO}

Os sujeitos envolvidos na pesquisa: para esse relato selecionamos quatro grupos específicos de uma determinada turma e traçamos um comparativo de seus projetos elaborados no $1^{\mathrm{o}}$ ano (2018) e no $2^{\mathrm{a}}$ nos (2019). A faixa etária dos alunos é de 14 a 17 anos e alguns tiveram, no ensino fundamental, uma experiência com a pesquisa científica de alguma forma (elaboração de projetos, feiras de ciências) e outros tem na escola o primeiro contato com a de iniciação científica. O Quadro 2 apresenta o título e o problema de pesquisa apresentados em seus projetos ao longo das duas disciplinas.

Quadro 2 - Exemplos de pesquisas

\begin{tabular}{|l|l|l|l|}
\hline Grupo & Ano & Título do projeto & Problema de pesquisa \\
\hline G1 & $1^{\text {o-d }}$ & $\begin{array}{l}\text { As principaiscausas do Alzheimer na região } \\
\text { metropolitana de porto alegre }\end{array}$ & $\begin{array}{l}\text { Quais as principais causas do Alzheimer na } \\
\text { região metropolitana de Porto Alegre? }\end{array}$ \\
\cline { 2 - 4 } & $2^{\text {o }}$ & $\begin{array}{l}\text { Sabão líquido ecológico à base de bicarbonato } \\
\text { de sódio }\end{array}$ & $\begin{array}{l}\text { O sabão ecológico à base de bicarbonato de sódio é } \\
\text { tão eficiente quanto o sabão industrializado? }\end{array}$ \\
\hline G2 & $1^{\circ}$ & $\begin{array}{l}\text { Cosmético vegano: beleza natural } \\
\text { Quais as matérias primas veganas e processos mais } \\
\text { adequados para a produção de um batom hidratante? }\end{array}$ \\
\hline G3 & $\begin{array}{l}\text { Análise comparativa dos resíduos sólidos } \\
\text { presentes na nascente, açude e foz de uma } \\
\text { propriedade privada em Taquara-RS }\end{array}$ & $\begin{array}{l}\text { É possível verificar se há interferência da piscicultura } \\
\text { no açude e em sua foz localizada em taquara-RS } \\
\text { através de análise das amostras coletadas na nascente, } \\
\text { no açude e foz, considerando as análises de sólidos } \\
\text { totais, sólidos sedimentáveis, sólidos suspensos e pH? }\end{array}$ \\
\hline & $1^{\text {o }}$ & $\begin{array}{l}\text { O impacto dos influenciadores digitais na vida } \\
\text { de jovens do primeiro ano do curso técnico de }\end{array}$ & $\begin{array}{l}\text { Como os influenciadores digitais impactam na vida } \\
\text { dos jovens do primeiro ano do Curso Técnico de }\end{array}$ \\
\hline
\end{tabular}




\begin{tabular}{|l|l|l|l|}
\hline \multirow{5}{*}{} & & $\begin{array}{l}\text { química da fundação Liberato Salzano Vieira } \\
\text { da Cunha. }\end{array}$ & $\begin{array}{l}\text { Química da Fundação Liberato Salzano Vieira Da } \\
\text { Cunha? }\end{array}$ \\
\cline { 2 - 4 } & $2^{\text {o }}$ & $\begin{array}{l}\text { Sabonete artesanal utilizando Malva sylvestris } \\
\text { G4 }\end{array}$ & $\begin{array}{l}\text { Éssível elaborar um sabonete artesanal com } \\
\text { propriedades anti-acne utilizando a } \\
\text { Malva sylvestris e avaliar sua eficiência? }\end{array}$ \\
\cline { 2 - 4 } & $1^{\text {o }}$ & $\begin{array}{l}\text { Agrião d'água, as condições mais adequadas } \\
\text { para um crescimento eficaz }\end{array}$ & $\begin{array}{l}\text { Qual dos micronutrientes, zinco e/ou cobre, e qual } \\
\text { fator de pH de água podem ser mais adequados para o } \\
\text { desenvolvimento eficaz no plantio de agrião d'água? }\end{array}$ \\
\hline $2^{\text {o }}$ & $\begin{array}{l}\text { Os benefícios dos micronutrientes cobre e zinco } \\
\text { no cultivo do agrião d'água }\end{array}$ & $\begin{array}{l}\text { Os micronutrientes, zinco e/ou cobre, podem fazer } \\
\text { com que o agrião d'água tenha um crescimento e } \\
\text { desenvolvimento mais eficaz? }\end{array}$ \\
\hline
\end{tabular}

Fonte: Autoras (2020).

No $1^{\circ}$ ano, dedicado à motivação para iniciação científica, investimos em temáticas livres, de acordo com o interesse dos alunos. Essa estratégia vem ao encontro da afirmação de Pozo (2002, p.146), “a motivação pode ser considerada como um requisito, uma condição prévia da aprendizagem". Quando o estudante tem interesse por determinada área, esse interesse "o impulsiona a se aprofundar nela e a vencer os obstáculos que possam ir se apresentando ao longo do processo de aprendizagem" (FITA, 1999, p. 78). Por isso é muito comum, projetos que envolvam temáticas diversas, como podemos observar: investigação sobre doenças como Alzheimer (G1), diabetes, doença celíaca, intolerância à lactose, depressão, ansiedade são temáticas recorrentes nas turmas. Além de pesquisa que envolvem dietas específicas, como a vegana e a vegetariana. Pesquisas sobre cosméticos (G2), cuidados com a pele e cabelos, tratamento de acne entre outros também são apresentados pelos alunos. O desenvolvimento e uso de tecnologias e sua relação com o aprendizado e o comportamento dos jovens (G3) está igualmente presente nos planos de pesquisa apresentados, e por fim alguns grupos, em menor números, já esboçam uma pesquisa relacionadas com conceitos químicos (G4).

Comparando os grupos no decorrer dos dois anos letivos, podemos observar um amadurecimento no processo de pesquisa como método e não menos importante a experiência do trabalho em grupo que, âs vezes, mostra-se como um grande desafio. Notamos que os grupos G1, G2 e G3 optaram por alterar seus projetos, usando temáticas relacionadas com a química, e o G4 fez uma adequação da temática escolhida no primeiro ano. Os alunos que participam da feira citam na avaliação pessoal dos trabalhos desenvolvidos, um grande aprendizado a experiência de participação na FEICIT, pois assim recebem críticas e sugestões de visitantes e avaliadores que mostram uma outra 
perspectiva na linha de pesquisa apresentada, tanto com contribuições, relatos e experiências como críticas.

No que se refere ao desenvolvimento dos alunos ao final do primeiro ano percebemos que eles possuem uma maior compreensão do que é o método científico, estão familiarizados com a leitura de textos científicos, diferenciam plágio de citação e já estão mais habituados à escrita de textos utilizando normas de formatação. Também desenvolvem as habilidades necessárias à elaboração e apresentação de trabalhos. No segundo ano os alunos iniciam a disciplina com certa segurança pois já tiveram essa experiência no ano anterior, no entanto, no decorrer dos trimestres são motivando a melhorar seus planos com a leitura de maior número de artigos científicos e conforme a metodologia vai sendo executada eles demonstram maior motivação e entusiasmo pelos resultados.

\section{CONSIDERAÇÕES FINAIS}

Ao comparamos a repercussão da disciplina no desenvolvimento das habilidades relacionadas ao processo de compreender e aplicar a metodologia científica na elaboração de uma pesquisa; torna-se claro que, apesar do tempo limitado para o desenvolvimento das atividades, que restringe o aprofundamento de alguns aspectos; há um impacto positivo com a alteração da dinâmica da disciplina. Com a nova organização distribuiu ao longo de dois anos as atividades necessárias a compreensão de conceitos básicos sobre pesquisa, elaboração de um planejamento e a execução de uma pesquisa como produto a divulgação científica dos resultados por meio de relatório e até mesmo apresentação em Feira de Ciências.

Por isso, reiteramos, a importância da Iniciação Científica no Ensino Médio, por ser uma

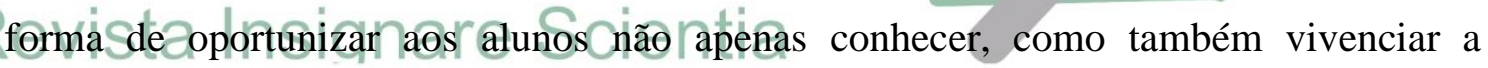
elaboração de uma pesquisa utilizando o método científico. Essa atividade permite ter uma noção da importância dos aspectos metodológicos e éticos na pesquisa. $\mathrm{O}$ esforço demandado, certamente resulta em uma aprendizagem significativa, além da compreensão de como o conhecimento científico é construído e do como ocorre o avanço científico e tecnológico na sociedade. A instauração da iniciação científica como componente curricular na escola, oportuniza que todos os alunos, e não apenas alguns, 
tenham acesso a essa aproximação com a ciência, ao desenvolvimento de uma visão crítica e ao estímulo pela busca do conhecimento.

\section{REFERÊNCIAS}

COSTA, L. D.; MELlO, G. J.; ROEHRS, M. M. Feira de Ciências: aproximando estudantes da educação básica da pesquisa de iniciação científica. Ensino em Re-Vista, v. 26, n. 2, p. 504-523, 30 jun. 2019.

DA COSTA, Washington Luiz; DE FREITAS ZOMPERO, Andreia. A iniciação científica no Brasil e sua propagação no Ensino Médio. Revista de Ensino de Ciências e Matemática, v. 8, n. 1, p. 14-25, 2017.

DA SILVA, Wellem Ribeiro et al. Iniciação científica na educação básica: percepção de representantes do Norte de Minas Gerais na SBPC 2017. Educação, Escola \& Sociedade, v. 10, n. 11, p. 45-62, 2018.

DEMO, Pedro. Desafios modernos da educação. In: Desafios modernos da educação. 2002. p. 272-272.

FERREIRA, Cristielly Silva; FERREIRA, Félkerson Marinho; SOARES, Brennda Cavalcante. DIFICULDADE NA ELABORAÇÃO DE TRABALHOS CIENTÍFICOS NO ÂMBITO ENSINO MÉDIO. In: $\mathbf{8}^{\mathbf{a}}$ JICE-JORNADA DE INICIAÇÃO CIENTÍFICA E EXTENSÃO. 2017.

FITA, E. C. O professor e a motivação dos alunos. In: TAPIA, J. A.; FITA, E. C. A motivação em sala de aula: o que é, como se faz. 4. ed. São Paulo: Loyola, 1999. p. 65135 .

GALLON, M.; SILVA, J.; NASCIMENTO, S.; ROCHA FILHO, J. Feiras de Ciências: uma possibilidade à divulgação e comunicação científica no contexto da educação básica. Revista Insignare Scientia - RIS, v. 2, n. 4, p. 180-197, 19 dez. 2019.

LIBERATO. Curso técnico em Química. Página inicial. 2020a Disponível em: < http://www.liberato.com.br/cursos-tecnicos/quimica>. Acesso em: 12 de mar. de 2020. 
Edição Especial: XVI Encontro sobre Investigação na Escola - EIE

LIBERATO. Comitê de Ética e Segurança na Pesquisa. 2020b. Disponível em:

<http://www.liberato.com.br/sites/default/files/arquivos/CESP/texto_2_b_-

_resolucao_criacao_cesp.pdf $>$. Acesso em: 12 de mar. de 2020.

MOSTRATEC. Mostra Internacional de Ciência e Tecnologia. 2020. Disponível em:

< http://mostratec.com.br/pt-br/mostratec/historia>. Acesso em: 12 de mar. de 2020.

POZO, J. I. Aprendizes e mestres: a nova cultura da aprendizagem. Porto Alegre: Artmed, 2002, 296 p.

SEVERINO, A. J. Metodologia do trabalho científico. São Paulo: Cortez, 2016.
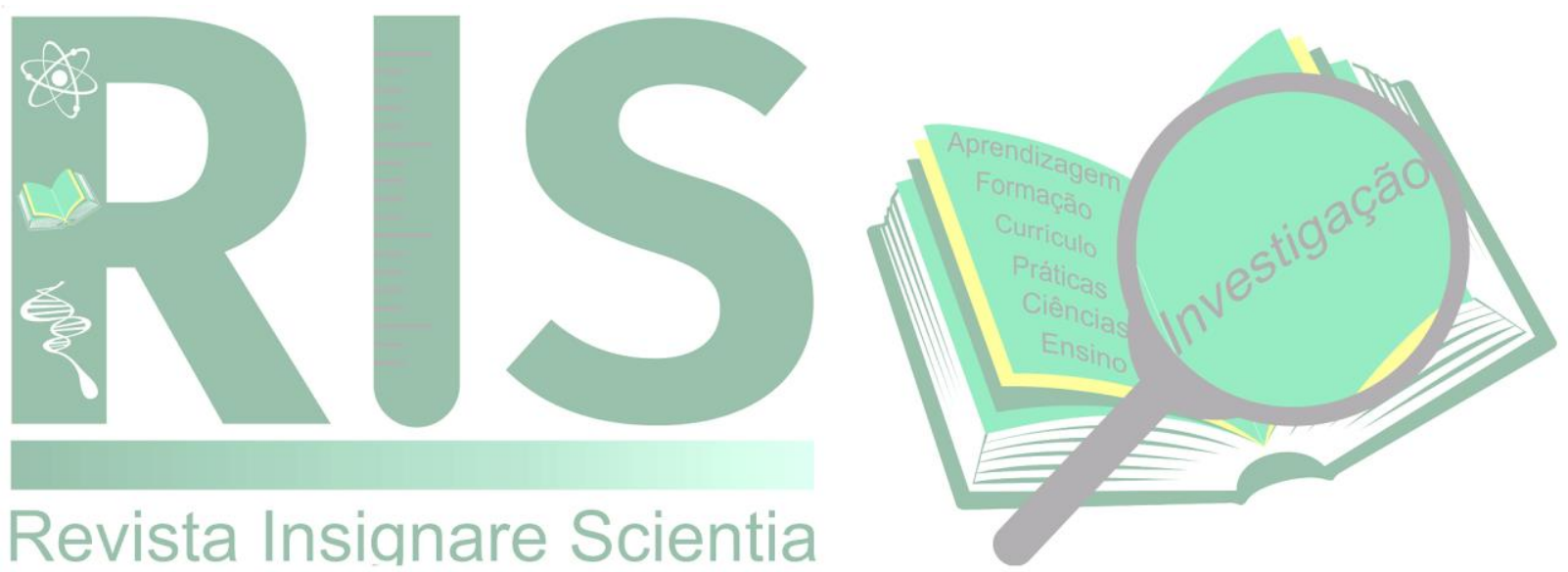

Recebido em: $30 / 04 / 2020$ 